\title{
Efficient Synthesis of Peptides with 4-Methylpiperidine as Fmoc Removal Reagent by Solid Phase Synthesis
}

\author{
Cristian Francisco Vergel Galeano, ${ }^{a}$ Zuly Jenny Rivera Monroy, ${ }^{\mathrm{b}}$ Jaiver Eduardo Rosas Pérez, ${ }^{\mathrm{a}}$ and Javier \\ Eduardo García Castañeda ${ }^{\mathrm{a}, *}$
}

a Departamento de Farmacia, bepartmento de Química, Facultad de Ciencias, Universidad Nacional de Colombia. Carrera 45 No. 26-85, Bogotá, Colombia. jaegarciaca@unal.edu.co

Received March 25th, 2014 ; Accepted May 19 ${ }^{\text {th }}, 2014$

\begin{abstract}
Solid phase peptide synthesis using the Fmoc/t-Bu strategy (SPPS-Fmoc/tBu) is the most widely used methodology for obtaining synthetic peptides. In this paper, we evaluate the viability of using 4-methylpiperidine as a reagent for deprotection of the amino acid alpha amino group in SPPS-Fmoc/tBu. For this purpose, the peptide (RRWQWRMKKLG) was simultaneously synthesized using 4-methylpiperidine or piperidine for Fmoc removal reagent. The obtained products had similar purities and yields. Finally, 21 peptides were synthesized using 4-methylpiperidine. Our results suggest that is possible to obtain synthetic peptides efficiently by the strategy SPPS-Fmoc/tBu when 4-methylpiperidine was used as reagent to remove Fmoc groups $\mathrm{N}$-alpha protected amino acids.

Keywords: Synthetic Peptide, piperidine, 4-methylpiperidine, Fmoc removal reaction, Solid Phase Peptide Synthesis.
\end{abstract}

\section{Introduction}

Merrifield developed a solid-phase peptide synthesis strategy by using the Boc/Bzl reagents, which is considered to be a versatile, efficient, economical, and rapid methodology for generating synthetic peptides [1]. However, the applicability of this methodology has shown some limitations due to the use of hydrofluoric acid for separation of the final peptide from the solid support. As an alternative, the SPPS-Fmoc/tBu methodology was developed in the 1970 's. This methodology requires mild conditions and an orthogonal protection system; amino acid side chains are protected by acid-labile groups, while the alphaamine group is protected with the base-labile Fmoc group [2-5]. The SPPS-Fmoc/tBu procedure is performed on a functionalized support allowing the addition of several amino acids until the target peptide is complete. The coupling reaction is carried out by pre-activation of the Fmoc-amino acid, forming a reactive ester [6]. The coupling reaction is possible if the alpha-amine group of the amino acid attached to a solid support is available for the reaction. Then, removal of the Fmoc group is carried out with a weak base such as piperidine (usually in DMF); however, sometimes the Fmoc-group removal is incomplete, due to several factors such as the specific amino acid sequence, the chain length, and steric hindrance caused by bulky protecting groups, or the presence of aggregates that hinder piperidine's access to reaction sites [7-8]. For these reasons, it is frequently
Resumen. La síntesis de péptidos en fase sólida mediante la estrategia Fmoc/tBu (SPFS-Fmoc/tBu) es la metodología más utilizada para la obtención de péptidos sintéticos. En este trabajo se evaluó la posibilidad de utilizar 4-metilpiperidina como reactivo para la desprotección del grupo alfa amino de aminoácidos en SPFS-Fmoc/tBu. Con este propósito, se sintetizó el péptido (RRWQWRMKKLG) de manera simultánea utilizando 4-metilpiperidina o piperidina como reactivo para la remoción del grupo Fmoc. Los productos obtenidos presentaron pureza y rendimiento similar. Adicionalmente, se sintetizaron 21 péptidos de diferente naturaleza fisicoquímica utilizando 4-metilpiperidina. Nuestros resultados sugieren que es posible la obtención de péptidos sintéticos de manera eficiente mediante la estrategia SPFS-Fmoc/tBu cuando se utiliza 4-metilpiperidina como reactivo para remover el grupo Fmoc de los aminoácidos protegidos.

Palabras clave: péptido sintético, piperidina, 4-metilpiperidina, eliminación de Fmoc, Síntesis de péptidos en fase sólida.

necessary to carry out several reaction cycles and use piperidine in high concentrations to ensure complete Fmoc group removal, which is based in a beta-elimination mechanism. Briefly, the base removes a tertiary proton from the fluorenyl group [5, $9,10]$, and then the dibenzofulvene (DBF) groups is formed, $\mathrm{CO}_{2}$ is produced in this process, and the alpha-amine group is available for the coupling reaction [2]. In this regard, the DBF group tends to form insoluble aggregates as a consequence of polymerization reactions $[2,5]$. Fortunately, the scavenger-like action exerted by piperidine also allows the formation of dibenzofulvene-piperidine adducts $\left(\varepsilon=7800 \mathrm{~cm}^{-1} \mathrm{M}^{-1}\right.$ at $\left.301 \mathrm{~nm}\right)$ via a Michael-type addition, which is soluble and easily eliminated by filtration $[5,8,11]$.

Piperidine in DMF is better for Fmoc removal in SPPS than in solution phase peptide synthesis due to (i) elimination of DMF is easier, (ii) solvent-dependent reversible scavenging of DBF by piperidine, and (iii) DBF polymerization at higher concentrations [5, 11]. For these reasons, piperidine $\left(\mathrm{p} K_{a} 11.22\right)$ is considered as an excellent Fmoc removal reagent in SPPS-Fmoc/tBu. Bases with higher $\mathrm{p} K_{a}$ values than piperidine are able to remove the Fmoc group with higher efficacy; however, they do not form the dibenzofulvene-base adduct, therefore the reaction equilibrium is not shifted toward product formation (some reactions are incomplete) and these bases also require enormous quantities of solvent [2, $8,11,12]$. To remove the Fmoc group in SPPS, a reagent 
must fulfill two requirements: (i) the capacity to extract the tertiary proton present in the fluorenyl group, and (ii) the ability to form the dibenzofulvene-base adduct in order to avoid DBF polymerization. Bases such as dicyclohexylamine, cis2,6-dimethylpiperidine, and 1,8-diazabicyclo[5,4,0]undec7-ene (DBU) can eliminate the Fmoc group in solution reactions, but they do not form adducts (i.e. no scavenger action), so their application in SPPS-Fmoc/tBu is limited. Additionally, some of these bases induce side reactions $[9,12$, 13].

Other examples of bases that have been studied are piperazine, mono- $N$-methyl, and $N$-phenyl derivatives such as cis-3,5-dimethylpiperidine, tris-(2-aminoethy1)amine, $N$-phenyl-cis-3,5-dimethylpiperidine, cyclohexylamine, 4-aminomethylpiperidine, hexamethylenimine, heptamethylenimine, and morpholine. It has been observed that these bases can efficiently eliminate the Fmoc group while forming the dibenzofulvene-base adduct; however, their use in SPPS-Fmoc/tBu has not been generalized [2, 14-16].

The use of methylpiperidine derivatives to remove the Fmoc group from amino acids has been reported. In this regard, it has been observed that 4-methylpiperidine is the best deprotecting reagent [12]. Reaction rates follow the following order: 4-methyl- > 3-methyl- > 2-methyl-piperidine. Nevertheless, even though some research groups have successfully used 4-methylpiperidine as an efficient reagent to remove the Fmoc group in SPPS, piperidine continues to be the reagent of choice for the SPPS-Fmoc/tBu methodology $[17,18]$. For decades, efforts have been made to replace piperidine in the SPPSFmoc/tBu method, because of its toxicity, low yield reactions, harmful effects to the environment, and its current legal status as a controlled substance (92/109/EC recommendation; it could be used as a precursor to obtain illegal psychotropic drugs [8]). Consequently, the piperidine market is controlled by regulatory entities worldwide. Currently it can be difficult to obtain piperidine commercially because suppliers are not willing to go through the cumbersome procedures required thus the use of piperidine requires a substantial effort which may not result in a reliable supply. In the present paper, we evaluated the viability of routinely replacing piperidine with 4-methylpiperidine in reactions to remove the Fmoc group to produce synthetic peptides with good yields using the SPPS-Fmoc/tBu method. It is worth mentioning that 4-methylpiperidine is not a controlled substance. We evaluated different experimental parameters for this reaction in SPPS-Fmoc/tBu; specifically, base concentration, reaction time, peptide physicochemical properties, as well as the length and the target amino acid sequence. The sequences selected for this paper are derived from proteins such as Lactoferrin, L1 of HPV-16, and IE62 of chickenpox. Our results show that piperidine can be substituted by 4-methylpiperidine in SPPS-Fmoc/tBu. These results suggest that it is possible to replace the most popular piperidine by routinely implementing SPPS-Fmoc/tBu using 4-methylpiperidine. Our work provides additional evidence supporting the use of 4-methylpiperidine as a viable and efficient reagent for Fmoc removal in peptide synthesis.

\section{Material and methods}

\section{General}

2-Chlorotrityl resin, Fmoc-Arg(Pbf)-OH, Fmoc-Asp(OtBu)$\mathrm{OH}, \quad$ Fmoc-Lys(Boc)-OH, Fmoc-Trp(Boc)-OH, Fmoc$\mathrm{Gln}(\mathrm{Trt})-\mathrm{OH}$, Fmoc- $\beta$-Ala-OH, Fmoc-Phe-OH, Fmoc-Met-OH, Fmoc-Leu-OH, Fmoc-Gly-OH, Fmoc-Ala-OH, Fmoc-Ile-OH, Fmoc-Glu(OtBu)OH, Fmoc-Thr(tBu)-OH, Fmoc-Ser(tBu)$\mathrm{OH}$, Fmoc-Val-OH, Fmoc-Asn(Trt)-OH, Fmoc-Pro-OH, Fmoc-Cys(Trt)-OH, Fmoc-His(Trt)-OH, Fmoc-Tyr(tBu)$\mathrm{OH}, \mathrm{Fmoc}-\mathrm{Lys}(\mathrm{Fmoc})-\mathrm{OH}, \quad$ 6-(Fmoc-amino)hexanoic acid (Fmoc-Ahx-OH), 1-hydroxybenzotriazole (HOBt), N,N- dicyclohexylcarbodimide (DCC) were purchased from AAPPTec (Louisville, KY, USA). N,N-diisopropylethylamine (DIPEA), triisopropylsilane (TIS), 1,2-ethanedithiol (EDT), acetic anhydride, piperidine, 4-methylpiperidine, pyridine, ninhydrin, phenol, and KCN were purchased from Sigma-Aldrich (St. Louis, MO, USA). Methanol, diethyl ether, N,N-dimethylformamide (DMF), absolute ethanol, dichloromethane (DCM), acetonitrile $(\mathrm{AcN})$, isopropyl alcohol (IPA), and trifluoroacetic acid (TFA) were obtained from Honeywell- Burdick \& Jackson (Muskegon, Michigan, USA). All reagents were used without further purification.

\section{Analytical methods}

Reverse phase HPLC (RP-HPLC) analysis was performed on an Agilent Eclipse XDB-C18 $(3.5 \mu \mathrm{m} 4.6 \times 150 \mathrm{~mm})$ column using an Agilent 1200 liquid chromatograph (Omaha, Nebraska, USA) with UV-Vis detector $(210 \mathrm{~nm})$. For the analysis of crude peptides $(20 \mu \mathrm{L}, 1 \mathrm{mg} / \mathrm{mL})$, a linear gradient was applied from $0 \%$ to $70 \%$ Solvent B $(0.05 \%$ TFA in AcN) in Solvent A $(0.05 \% \mathrm{TFA}$ in water) for $45 \mathrm{~min}$ at a flow rate of $1.0 \mathrm{~mL} / \mathrm{min}$ at room temperature.

Peptides were purified using solid phase extraction columns (SUPELCO LC-18 with $1.0 \mathrm{~g}$ resin). SPE columns were activated prior to use with $30 \mathrm{~mL}$ acetonitrile (containing 0.1 $\%$ TFA) and equilibrated with $30 \mathrm{~mL}$ water (containing $0.1 \%$ TFA). Crude peptides were passed through the column, and a gradient was used for their elution. Collected fractions were analyzed using RP-HPLC (as describe above) and MALDITOF MS.

MALDI-TOF MS analysis was performed on an Ultraflex III TOF-TOF mass spectrometer (Bruker Daltonics, Bremen, Germany) in reflectron mode, using an MTP384 polished steel target (BrukerDaltonics), 2,5-dihydroxybenzoic acid, or sinapinic acid as a matrix; Laser: 500 shots and $25-30 \%$ power.

\section{Fmoc-Val-OH calibration curve, analysis by UV}

Fmoc-Val-OH stock solution $(25 \mathrm{~mL}, 500 \mu \mathrm{g} / \mathrm{mL})$ was prepared in DMF. To get 147.2 $\mu \mathrm{M}$ Fmoc-Val-OH $(50 \mu \mathrm{g} / \mathrm{mL})$, the stock solution was diluted ten times with DMF in a volumetric flask $(50.0 \mathrm{~mL})$. Then solutions of different concentrations 
were prepared (ranging from 14 to $118 \mu \mathrm{M}$ ) using as a starting material 147.2 $\mu \mathrm{M}$ Fmoc-Val-OH solution and DMF; finally, absorbance of each solution was measured at $302 \mathrm{~nm}(\mathrm{n}=3)$.

\section{Fmoc-Val-OH calibration curve, analysis using RP-HPLC}

$10.0 \mathrm{~mL}$ of Fmoc-Val-OH solution $(12.5 \mathrm{mg} / \mathrm{mL})$ was diluted to $100.0 \mathrm{~mL}$ with HPLC grade Acetonitrile, obtaining a 3679 $\mu \mathrm{M}$ stock. Then solutions of different concentrations, ranging from 0 to $3000 \mu \mathrm{M}$, were prepared. Each solution $(20 \mu \mathrm{L})$ was analyzed through RP-HPLC using Agilent Eclipse XDB-C18 $(3.5 \mu \mathrm{m} 4.6 \times 150 \mathrm{~mm})$ column; detection was performed at $302 \mathrm{~nm}$. For the analysis, a lineal gradient from 10 to $100 \%$ of Solvent B in Solvent A was used at $1 \mathrm{~mL} / \mathrm{min}$ flow rate. Gradient time was 15 minutes.

\section{Analysis through RP-HPLC of Fmoc removal kinetics}

Fmoc-Val-OH (250.0 mg) was dissolved in $25.0 \mathrm{~mL}$ of piperidine solutions whose concentrations were 1, 2, 5, and 20\% (v/v) in DMF. Then $50 \mu \mathrm{L}$ aliquots were taken from each solution at different times $(0,1,3$ and $5 \mathrm{~min})$, and diluted to $1.0 \mathrm{~mL}$ with Solvent B. After that, solutions were diluted twice with Solvent A. Finally, each solution was analyzed using RP-HPLC under the conditions described above.

\section{Dibenzofulvene-base adduct calibration curves, analysis by UV}

Fmoc-Val-OH stock solutions $(500 \mu \mathrm{g} / \mathrm{mL})$ were prepared in (a) piperidine $(20 \% \mathrm{v} / \mathrm{v})$ in DMF or (b) 4-methylpiperidine $(20 \% \mathrm{v} / \mathrm{v})$ in DMF. Fmoc removal reactions were stirred for 30 min at room temperature. Then, $5.0 \mathrm{~mL}$ of each stock solution was diluted to $50.0 \mathrm{~mL}$ with (a) piperidine $(20 \% \mathrm{v} / \mathrm{v})$ in $\mathrm{DMF}$ or (b) 4-methylpiperidine $(20 \% \mathrm{v} / \mathrm{v})$ in DMF. Finally, different dibenzofulvene-base solutions were prepared, ranging from 15 to $120 \mu \mathrm{M}$ and measured at $302 \mathrm{~nm}(n=3)$.

\section{Dibenzofulvene-base adduct formed from Rink amide resin. Calibration curve by $\mathrm{UV}$}

Various amounts of Rink amide resin $(5,10,15,20,25$, and $30 \mathrm{mg}$ ) were measured and introduced into $25.0 \mathrm{~mL}$ volumetric flasks; then each flask was brought to the correct volume mark with 4-methylpiperidine (20\% v/v in DMF). Fmoc removal reactions were stirred at room temperature for $30 \mathrm{~min}$. After that, $10.0 \mathrm{~mL}$ of each solution was diluted to $50.0 \mathrm{~mL}$ with 4-methylpiperidine $(20 \% \mathrm{v} / \mathrm{v}$ in DMF) and filtered. Finally, the absorbance of each diluted solution was measured at 302 $\mathrm{nm}(n=3)$.

\section{Solid Phase Peptide Synthesis (SPPS-Fmoc/tBu)}

Peptide 1 (RRWQWRMKKLG) was synthesized simultaneously via SPPS-Fmoc/tBu using either piperidine or 4-methylpiperidine $(20 \% \mathrm{v} / \mathrm{v}$ in DMF) as the Fmoc removal reagent.
Peptide 1 was synthesized using the manual methodology implemented in our laboratory for SPPS-Fmoc/tBu. Briefly, Rink Amide resin (150 mg, 0.46meq/g) was used as solid support. (i) In order to release the amine group from the resin, it was treated twice with the Fmoc removal reagent for 10 minutes, and then the resin was washed with DMF (5x), IPA (3x), and DCM (3x). (ii) For the coupling reaction, $0.21 \mathrm{mmol}$ of Fmoc-amino acids was pre-activated with DCC/HOBt $(0.20 / 0.21 \mathrm{mmol})$ in DMF. The pre-activation mixture was continuously stirred at room temperature (RT) for 15 min. After that, the activated Fmocamino acid was added to a reactor containing the deprotected resin; the coupling reaction was stirred for two hours at RT, and then the resin was washed with DMF and DCM. (iii) Fmoc group elimination and the incorporation of each amino acid were confirmed by the ninhydrin test [19]. Side chain deprotection reactions and peptide separation from the solid support were carried out with a "cleavage" cocktail containing TFA/ water/TIS/EDT (93/2/2.5/2.5\% v/v), the reaction was stirred for $6 \mathrm{~h}$ at RT, then the mixture was filtered, and the solution was collected. Crude peptides were precipitated by treatment of the filtered solution with cold ethyl ether, and finally they were washed with ether five times. The crude products were analyzed using RP-HPLC and MALDI-TOF MS as it was described in analytical methods.

The following peptides were synthesized using the methodology described above and 4-methylpiperidine (20\% v/v in DMF) as the Fmoc removal reagent: $\beta A-R R W Q W R, \beta A-$ RRWQWRMKKLG, RRWQWRMRRLG, (RRWQWR) ${ }_{2} \mathrm{~K}-$ $A h x$-C, FK- $\beta A-R R W Q W R M K K L G-\beta A$, K- $\beta A-R R W Q W R M-$ KKLG- $\beta A, \quad \beta A-R R W Q W R M R R L G, \quad A c-\beta A-R R W Q W R$, FK- $\beta A-R R-\beta A-Q-\beta A-R M K K L G A, \quad$ ADLLDMLELTD, ILARYQRAPDGL, YAMSAFARRLSQ, PDDVLRAITEPT, RSQAALDKTGDF, IHSMNSTIL, MKIPNNKLFLPV, SPINNTKPHEAR, C- $A h x$-IHSMNSTIL $\quad$ C- $A h x$-MKIPNNKLFLPV, C- $A h x$-SPINNTKPHEAR, and (YIK) $)_{2} \mathrm{~K}-A h x-\mathrm{C}$.

\section{Results and discussion}

Fmoc-Val-OH was chosen as a model to evaluate the formation of the DBF adduct. As a first step, its UV spectrum in DMF was determined (data not shown). Due the fact that its absorption at $302 \mathrm{~nm}$ is mainly caused by the Fmoc group, this wavelength was selected to prepare two calibration curves: (i) Fmoc-Val$\mathrm{OH}$ concentration $(\mu \mathrm{M})$ versus absorbance. This curve showed a linear correlation $\left(y=0.0066 x+0.0054 ; \mathrm{R}^{2}=0.9999\right)$; the Fmoc-Val-OH absorption coefficient in DMF at $302 \mathrm{~nm}$ was determined to be $6700 \mathrm{~cm}^{-1} \mathrm{M}^{-1}$. (ii) Fmoc-Val-OH concentration $(\mu \mathrm{M})$ versus area. This curve was built using data obtained from the RP-HPLC analysis at $302 \mathrm{~nm}$. The Fmoc-Val-OH chromatographic profile only showed a peak at $t_{\mathrm{R}}=13.0 \mathrm{~min}$. The peak area increased linearly $\left(y / 10^{6}=0.0756 x+2.3909 ; \mathrm{R}^{2}\right.$ $=0.9992$ ) with the Fmoc-Val-OH concentration (ranging from 0 to $3000 \mu \mathrm{M})$.

The kinetics of Fmoc removal reaction from Fmoc-Val$\mathrm{OH}$ was studied using piperidine as the deprotection reagent; 
i.e. different piperidine concentrations and different reaction times were analyzed through RP-HPLC (Fig. 1). The reaction chromatographic profile at time zero only showed a peak $\left(t_{\mathrm{R}}=\right.$ 13.0 minutes) whose area corresponded to $745 \mu \mathrm{M}$ of FmocVal-OH calculated using $y=0.0066 x+0.0054$ equation. When piperidine $1 \%(\mathrm{v} / \mathrm{v})$ in DMF was used as the Fmoc removal reagent at Time $1(1 \mathrm{~min})$ the reaction chromatogram showed two peaks which correspond to Fmoc-Val-OH and DBF $\left(t_{\mathrm{R}}\right.$ $=15.8$ minutes) and the calculated Fmoc removal was 5.2\%. Time 2 and 3 Chromatograms ( 3 and 5 min, correspondingly) show that DBF peak area increases and Fmoc-Val-OH peak area decreases, the Fmoc group elimination was $33.4 \%$ and $49.6 \%$, respectively (Fig. 1A). The reaction kinetics with $2 \%$ piperidine shows a similar pattern (Fig. 1B); the Fmoc group elimination was $12.9 \%, 63.3 \%$ and $87.9 \%$ at Time 1 , Time 2 and Time 3, correspondingly. When 5\% (Fig. 1C) or 20\% piperidine (data not shown) was used, the Fmoc removal was completed (>99\%) after 3 minutes (Time 2 ). According to these
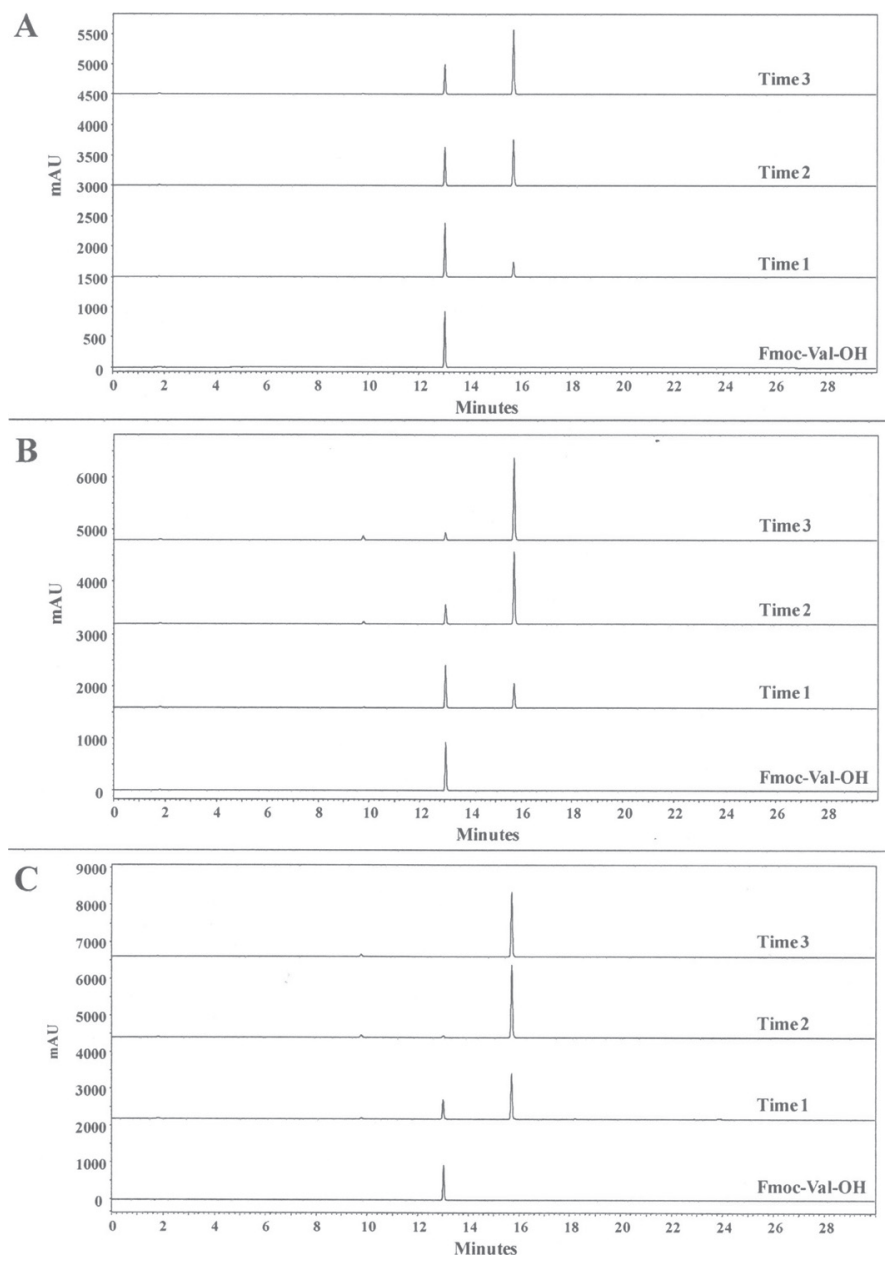

Fig. 1. Analysis of Fmoc removal reaction kinetics through RP-HPLC. Fmoc-Val-OH was used as a starting material. As the Fmoc removal reagent piperidine was used in DMF in the following concentrations $(\% \mathrm{v} / \mathrm{v}): 1 \%$ (panel A), $2 \%$ (panel B) or 5\% (panel C). Reaction time: 1 min (Time 1), 3 min (Time 2), 5 min. (Time 3). Fmoc-Val-OH $\left(t_{\mathrm{R}}\right.$ $=13.0 \mathrm{~min}$.$) and \mathrm{DBF}\left(t_{\mathrm{R}}=15.8 \mathrm{~min}\right)$. results, when piperidine is used in a concentration equal to or bigger than $5 \%$, it can be guaranteed that the Fmoc removal reaction in solution will proceed in a quantitative way after 3 minutes of reaction.

When the reaction of Fmoc-Val-OH with $20 \%$ piperidine in DMF was stopped at 5 min by dilution with DMF and analyzed through RP-HPLC (Fig. 2A), it is interesting to note that the chromatographic profile shows a principal peak at $t_{\mathrm{R}}$ $=9.8 \mathrm{~min}$, corresponding to the dibenzofulvene-piperidine adduct (according to Carpiño L et al. [5]) and a small peak at $t_{\mathrm{R}}$ $=15.8 \mathrm{~min}$., corresponding to DBF. On the other hand, when the reaction was stopped by dilution using Solvent B (Fig. 2B), the DBF signal $\left(t_{\mathrm{R}}=15.8 \mathrm{~min}\right)$ is mainly observed; this result suggests that Solvent B (acetonitrile in acid medium) is able to dissociate the dibenzofulvene-piperidine adduct and regenerate the DBF.

Various concentration solutions of Fmoc-Val-OH were treated with $20 \%$ base (piperidine or 4-methylpiperidine) in DMF for 30 min to ensure that the Fmoc removal reaction was quantitatively completed. Then these solutions were measured at $302 \mathrm{~nm}$, where absorption was due exclusively to the dibenzofulvene-base adduct. Finally, using the obtained data, calibration curves of dibenzofulvene-base adduct concentration versus absorbance were built, showing a linear relation for both adducts (Fig. 3A and 3B). Additionally, these graphics allowed calculating the absorptivity for the dibenzofulvene-piperidine adduct $\left(\varepsilon=8500 \mathrm{~cm}^{-1} \mathrm{M}^{-1}\right)$ and for the dibenzofulvene-4-methylpiperidine adduct $\left(\varepsilon=8200 \mathrm{~cm}^{-1} \mathrm{M}^{-1}\right)$. Our results are close to those reported by Jensen, J. K. et al. (dibenzofulvene-piperidine adduct, $\varepsilon=7800 \mathrm{~cm}^{-1} \mathrm{M}^{-1}$ at $301 \mathrm{~nm}$ ) [20].

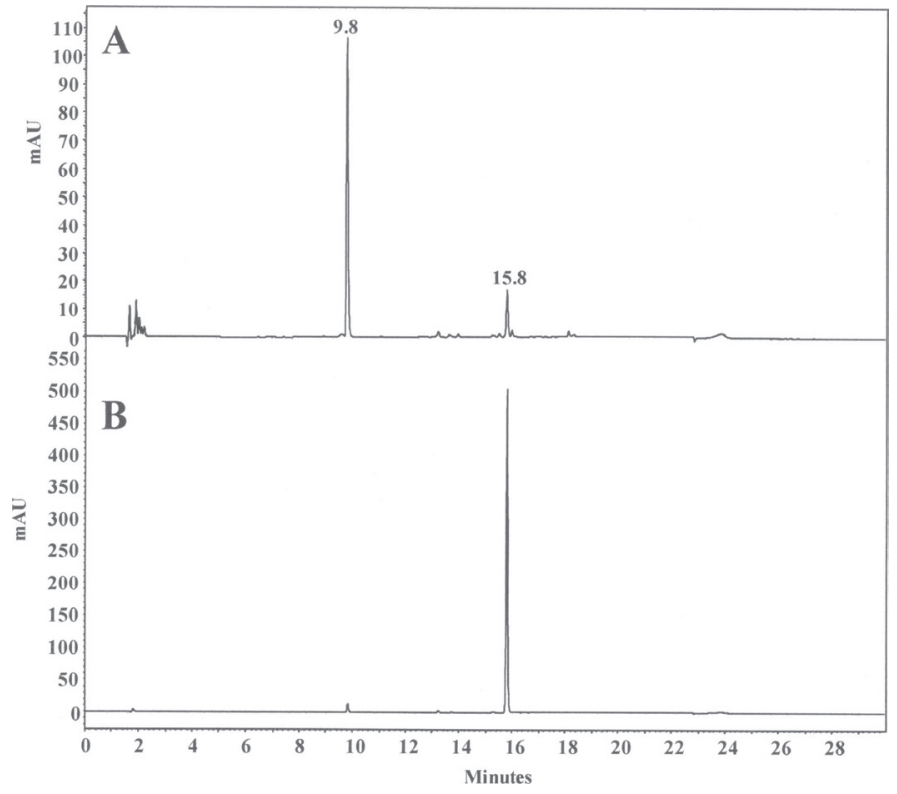

Fig 2. Reaction of Fmoc-Val-OH with $20 \%$ piperidine in DMF was analyzed through RP-HPLC. Fmoc removal reaction was stopped at 5 min by dilution with DMF (panel A) or AcN-0.05\% TFA (panel B). Dibenzofulvene-piperidine adduct $\left(t_{\mathrm{R}}=9.8 \mathrm{~min}\right.$.); Fmoc-Val-OH $\left(t_{\mathrm{R}}\right.$ $=13.0$ min. $)$ and $\mathrm{DBF}\left(t_{\mathrm{R}}=15.8 \mathrm{~min}.\right)$. 

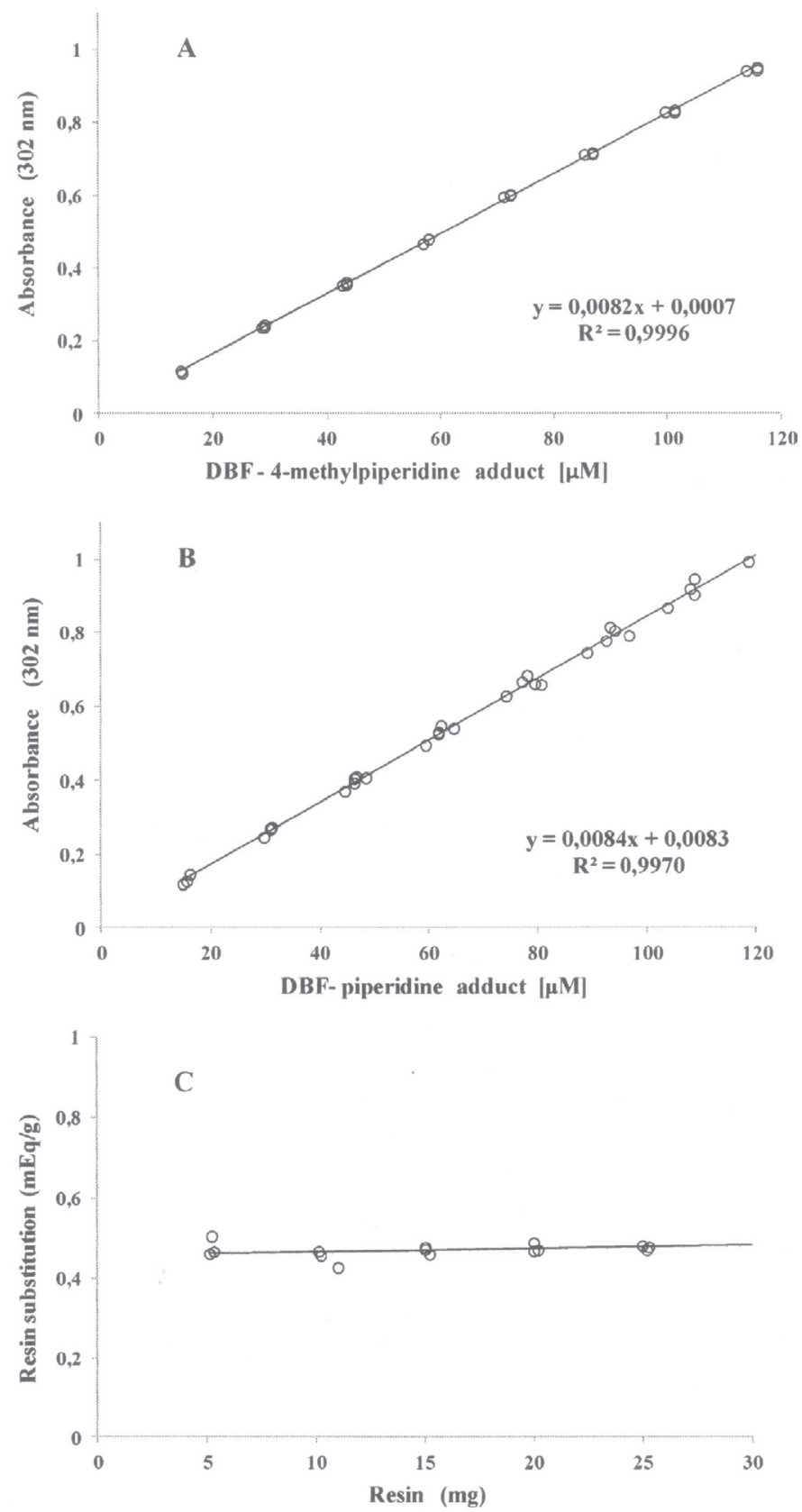

Fig. 3. Calibration curves. dibenzofulvene-base adduct $(\mu \mathrm{M})$ vs. Absorbance, using Fmoc-Val-OH as starting material and as the Fmoc removal reagent $20 \%$ (v/v) 4-methylpiperidine (Panel A) or 20\% piperidine (Panel B) in DMF. Resin substitution $(\mathrm{mEq} / \mathrm{g})$ vs. resin quantity (mg) (Panel C), using Rink resin as a starting material and 20\% 4methylpiperidine in DMF.

To study the behavior of 4-methylpiperidine in SPPS as the Fmoc removal reagent, various quantities of Rink amide resin were treated with $20 \%(\mathrm{v} / \mathrm{v})$ 4-methylpiperidine in DMF for 30 $\mathrm{min}$, and then the absorbance of the solutions was measured at $302 \mathrm{~nm}$. This result was compared with the one obtained when piperidine was used. Similarly to the result generated for the reaction in solution, the plot shows a linear relation between the dibenzofulvene-4-methylpiperidine adduct concentration and the absorbance (Data not shown). Additionally, using this data, the resin substitution was calculated, and the mean was 0.47 $\mathrm{mEq} / \mathrm{g}$, with a standard deviation of $0.02 \mathrm{mEq} / \mathrm{g}$ (Fig. 3C).

According to Zinieris N. et al. [8], when Fmoc-Val-OH is attached to a resin, Fmoc removal is complete $(99.99 \%)$ using piperidine $20 \%$ in DMF for 9 min. However, when the concentration of piperidine is reduced to $5 \%$ in DMF, the time required to obtain a complete deprotection reaction increases to $10.4 \mathrm{~min}$. As was discussed before, we observed that the Fmoc removal reaction takes place faster in solution than in solid phase, and even when using piperidine 5\% in DMF the reaction was completed in 3 minutes. Therefore, in order to ensure complete Fmoc group removal during the synthesis of peptides by SPPS-Fmoc/tBu, we decided to use an Fmoc removal reagent (piperidine or 4-methylpiperidine) in a concentration of $20 \%(\mathrm{v} / \mathrm{v})$ in DMF. We chose as a model Peptide 1 (RRWQWRMKKLG), whose sequence belongs to a fragment of bovine lactoferricin protein. Simultaneously, two solid phase synthesis of Peptide 1 were performed under the same experimental conditions. The only difference between the syntheses was the Fmoc removal reagent used, (i) $20 \%$ piperidine or (ii) $20 \%$ 4-methylpiperidine in DMF. For Fmoc removal of each protected amino acid attached to a solid support, the resin was treated twice with the reagent for 10 minutes, with constant shaking at RT. Crude peptide 1 obtained through SPPS using 4methylpiperidine was $74 \mathrm{mg}$ (70\% yield), and using piperidine it was $75 \mathrm{mg}$ (71\% yield), indicating that replacing piperidine with 4-methylpiperidine does not significantly affect the synthesis yield. Chromatographic profile of crude peptides from
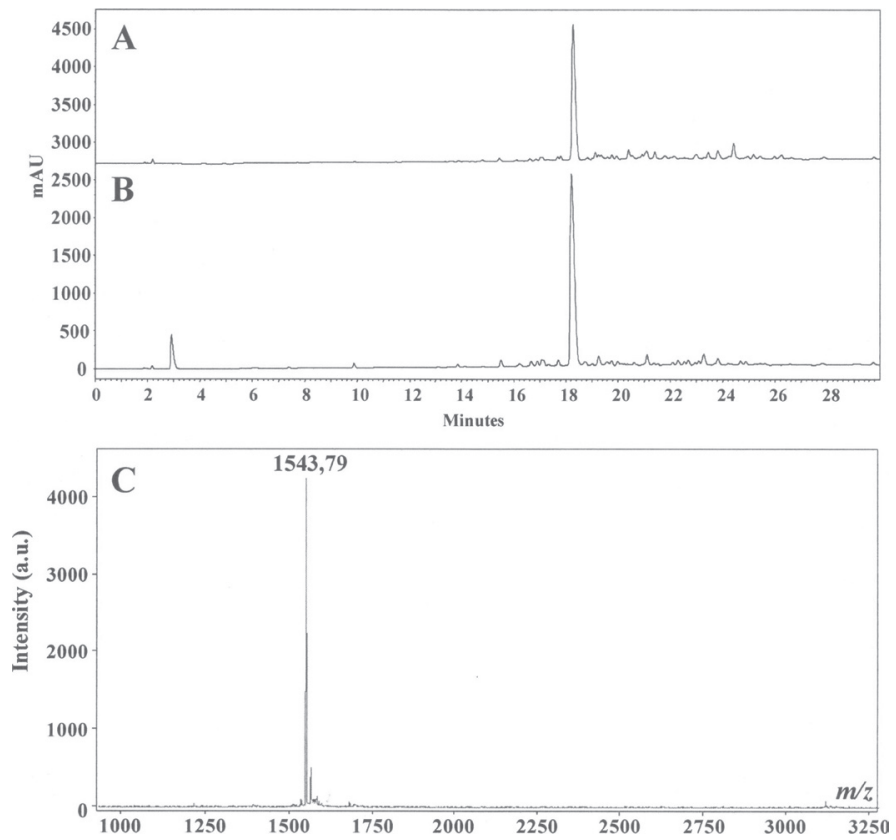

Fig. 4. Chromatographic profile of crude Peptide 1 obtained through SPPS-Fmoc/tBu using 4- methylpiperidine (panel A) or piperidine (panel B) $\left(t_{\mathrm{R}}=18.2 \mathrm{~min}\right.$.). MALDI-TOF MS analysis of purified Peptide 1 synthesized through SPPS-Fmoc/tBu using 4-methylpiperidine (panel C), $m / z=1543.79[\mathrm{M}+\mathrm{H}]^{+}$; calculated $[\mathrm{M}+\mathrm{H}]^{+}: 1543.87$. 
Table 1. Peptides synthesized through SPPS-Fmoc/tBu using 4-methylpiperidine (20\% in DMF) as the Fmoc removal reagent. Characterization of crude products using RP-HPLC and MALDI-TOF MS. * signal corresponds to $[\mathrm{M}+\mathrm{Na}]^{+}$.

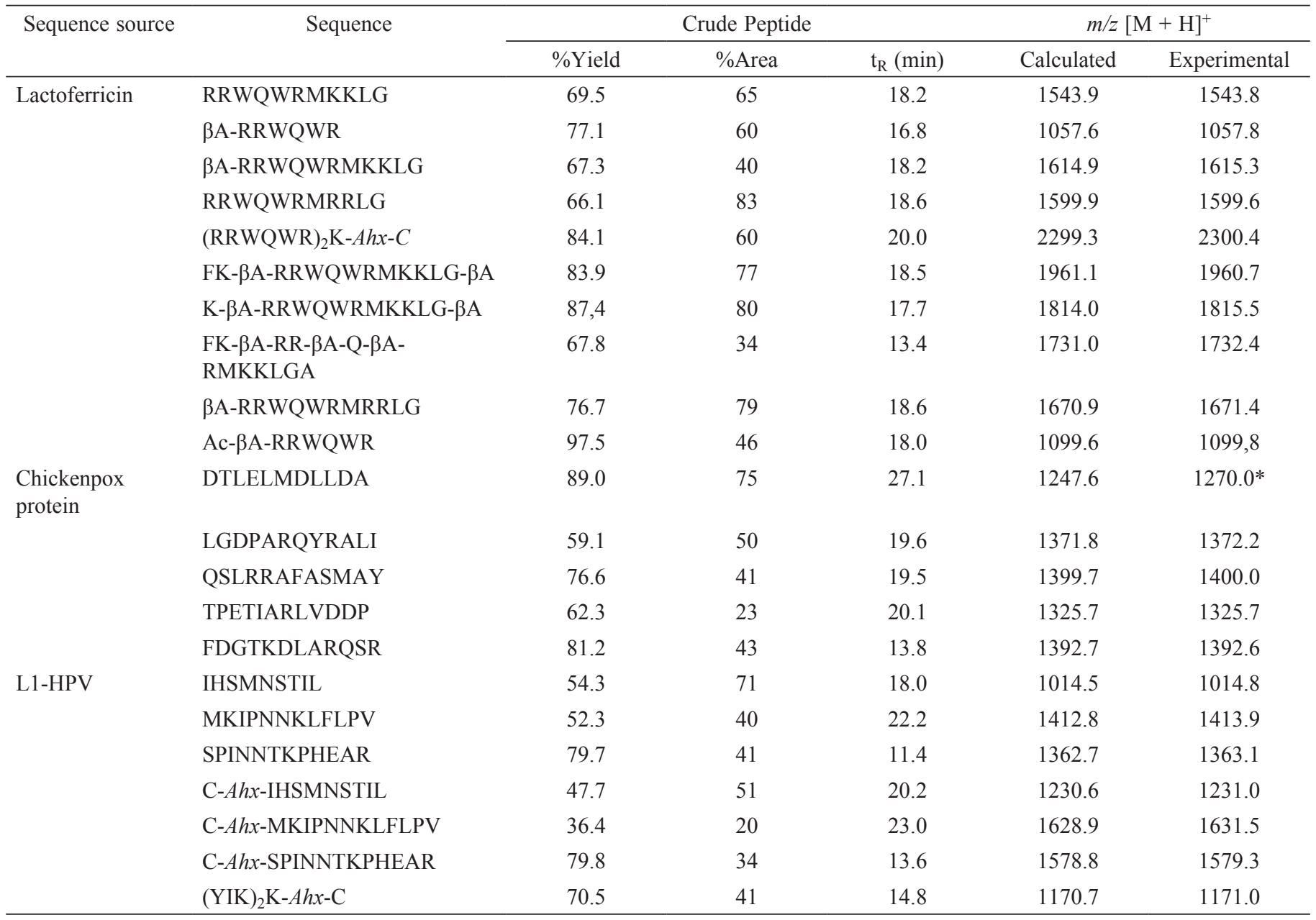

both syntheses showed a main peak at the same retention time, i.e. $t_{\mathrm{R}}=18.2 \mathrm{~min}$. (Fig. $4 \mathrm{~A}$ and $4 \mathrm{~B}$ ). In both profiles, some undesired species corresponding to possible deletions and subproducts of cleavage were observed. These results indicate that crude peptides were obtained with similar characteristics regardless of the reagent (piperidine or 4-methylpiperidine) used to remove it. Crude peptides were purified by liquid chromatography using columns $(\mathrm{C}-18)$ for solid phase extraction. The purified peptides were then analyzed using MALDI-TOF mass spectrometry (Fig. 4C); the results show that the molecular weight of both peptides correspond to the theoretical molecular weight, $\left([\mathrm{M}+\mathrm{H}]^{+}:\right.$1543,87).

Similarly, other peptides derived from Lactoferricin, L1 of HPV-16, and a chickenpox protein were synthesized through SPPS-Fmoc/tBu using 4-methylpiperidine as an Fmoc removal reagent (Table 1). It should be noted that the synthesized peptides possess different physicochemical characteristics such as amino acid sequence and chain length, some peptides contain non-natural amino acids such as beta-alanine $(\beta \mathrm{A})$ or 6 -aminohexanoic acid $(A h x)$, and some peptides are dimers. This result suggests that the use of 4-methylpiperidine has the same versatility as piperidine in SPPS-Fmoc/tBu. These results are in accordance with those obtained by Hachmann, J. and Lebl $\mathrm{M}[17]$.

\section{Conclusion}

This research provides evidence to support the use of 4-methylpiperidine in the SPPS-Fmoc/tBu methodology; our results demonstrated that no significant difference from those obtained when the SPPS-Fmoc/tBu procedure is carried out with piperidine as the Fmoc removal reagent. Furthermore, our results suggest that the experimental conditions used in our protocol to deprotect different amino acid sequences using 4-methylpiperidine in SPPS-Fmoc/tBu, produced a wide variety of peptides possessing different physicochemical characteristics and different amino acid sequences, including non-natural amino acids.

\section{Acknowledgements}

This research was conducted with the financial support of COLCIENCIAS, code 110151928802; contract 301-2010. 


\section{References}

1. Merrifield, R. B. J. Am. Chem. Soc. 1963, 85, 2149-2154.

2. Carpino, L. A. Acc. Chem. Res. 1987, 20, 401-407.

3. Carpino, L. A.; Han, G. Y. J. Am. Chem. Soc. 1970, 92, 57485749.

4. Athertohn, E.; Fox, H.; Harkissc, D.; Logan, J. C.; Sheppard, R. C.; Williams, B.J. J. Chem. Soc., Chem. Commun. 1978, 13, 537539.

5. Carpino, L. A.; Han, G. Y. J Org. Chem. 1972, 37, 3404-3409.

6. Fields, G.; Noble, R. Int. J. Peptide Protein Res. 1990, 35, 161214.

7. Larsen, B.; Holm, A. Int. J. Peptide Protein Res. 1994, 43, 1-9.

8. Zinieris, N.; Leondiadis, L.; Ferderigos, N. J. Comb. Chem. 2005, 7, 4-6.

9. Várady, L.; Rajur, S.; Nicewonger, R.; Guo, M.; Ditto, L. J. Chrom. A. 2000, 869, 171-179.

10. Bodanszky, M.; Deshmane, S.; Martinez, J. J. Org. Chem. 1979, $44,1622-1625$
11. Rawer, S.; Roeder, R.; Henklein, P. J Pept Sci. 2006, 12, Issue S1. 29th European Peptide Symposium.

12. Orain, D.; Ellard, J.; Bradley, M. J. Comb. Chem. 2002, 4, 1-16.

13. Sheppeck, J. E.; Kar, H.; Hong, H. Tetrah. Lett. 2000, 41, 53295333.

14. Isidro-Llobet, A.; Alvarez, M.; Albericio, F. Chem. Rev. 2009, 109, 2455-2504.

15. Carpino, L. A.; Sadat-Aalaee, D.; Beyermann, M. J. Org. Chem. 1990, 55, 1673-1675.

16. Beyermann, M.; Bienert, M.; Niedrich, H.; Carpino, L.; SadatAalaee, D. J. Org. Chem. 1990, 55, 721-728.

17. Hachmann, J.; Lebl, M. J. Comb. Chem. 2006, 8, 149.

18. Shiryaev, S.; Kozlov, I.; Ratnikov, B.; Smith, J.; Lebl, M.; Strongin, A. Y. Biochem. J. 2007, 401, 743-752.

19. Sarin, V. K.; Kent, S. B.; Tam, J. P.; Merrifield, R. B. Anal. Biochem. 1981, 117, 147-157.

20. Jensen, J. K.; Alsina, J.; Songster, F. M.; Vagner, J.; Albericio, F.; Barany, G. J. Am. Chem. Soc. 1998, 120, 5441. 